\title{
Walking as a meaningful leisure occupation: the implications for occupational therapy
}

Wensley, R

http://hdl.handle.net/10026.1/1242

10.4276/030802212X13286281651117

The British Journal of Occupational Therapy

All content in PEARL is protected by copyright law. Author manuscripts are made available in accordance with publisher policies. Please cite only the published version using the details provided on the item record or document. In the absence of an open licence (e.g. Creative Commons), permissions for further reuse of content should be sought from the publisher or author. 


\title{
Walking as a meaningful leisure occupation: the implications for occupational therapy
}

\author{
Ruth Wensley ${ }^{1}$ and Anita Slade ${ }^{2}$
}

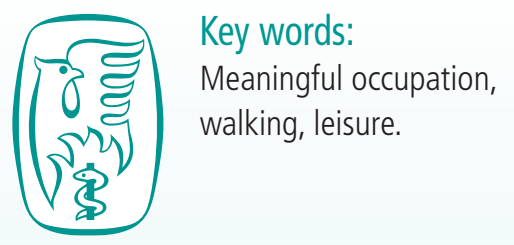

${ }^{1}$ Senior II Occupational Therapist, Occupational Therapy Department, Royal Hospital for Neuro-disability, London.

${ }^{2}$ Lecturer in Occupational Therapy, Peninsula Allied Health Centre, Faculty of Health, Education and Society, Plymouth University, Derriford, Plymouth.

Corresponding author: Ruth Wensley, Senior II Occupational Therapist, Occupational Therapy Department, Royal Hospital for Neuro-disability, West Hill, Putney, London SW15 3SW. Email: rwensley@rhn.org.uk

Reference: Wensley R, Slade A (2012) Walking as a meaningful leisure occupation: the implications for occupational therapy. British Journal of Occupational Therapy, 75(2), 85-92.

DOI: 10.4276/030802212X13286281651117

(C) The College of Occupational Therapists Ltd. Submitted: 25 January 2011.

Accepted: 5 December 2011.
Introduction: In response to growing interest in leisure in occupational therapy and the importance of understanding how occupations maintain, enhance and promote health and wellbeing, a qualitative phenomenological study was conducted to explore the experiences of walking for leisure.

Method: Six healthy student participants, identified as regular walkers, were interviewed using a semi-structured format. Data were analysed following interpretative phenomenological analysis methodology.

Findings: Participants expressed how and why walking was meaningful to them; the four main themes were social connectedness, wellbeing, connection to nature and achievement from a challenge. Findings suggest that occupational therapists could use walking and leisure occupations in intervention, and that there is scope for an occupational therapy perspective in health promotion.

Conclusion: Determining the subjective meaning of engaging in walking as a leisure occupation has implications for occupational science and health promotion in helping to explain why people do what they do.

\section{Introduction}

Walking is an easy everyday activity that most of us do automatically. However, recently, walking has been employed by health promotion strategists to improve the health of the general public, and used therapeutically in settings such as psychiatric services (McDevitt et al 2005, Richardson et al 2005). Studies have demonstrated its physiological and psychological benefits in alleviating depression in clinical and non-clinical populations (Richardson et al 2005, Dawson et al 2006, Roe and Aspinall 2011). Although the health benefits for physical activity have received increasing research attention, occupational benefits specific to walking are not well developed.

Participating in leisure occupations enhances physical wellbeing, mental health and social functioning (Ball et al 2007), personal satisfaction and growth (Mosey 1996), as well as contributing to personal and social identity (Taylor 2003). Leisure is 'a shared human experience engaged in for the purpose of amusement, relaxation or self-actualisation' (Mosey 1996, p80). Leisure occupations have received heightened attention in occupational therapy (Di Bona 2000), perhaps due to providing wellness and health promotion in the community (Wilcock 1998, College of Occupational Therapists [COT] 2008).

The benefits of leisure have been researched extensively (Taylor 2003, Ball et al 2007) but Di Bona (2000) recommended more research into leisure as an occupation to understand its potential benefits and to provide evidence to support its use in practice. Johnson (1996) believed that the more we understand how occupations maintain, enhance and promote health and wellbeing, the more we can put this knowledge into practice.

Despite this, literature focusing specifically on the meaning of walking as a leisure occupation is limited. 


\section{Occupation}

Occupational therapists believe that people have an intrinsic drive to be active and that engaging in satisfactory, meaningful occupations is a key therapeutic tool in promoting health and wellbeing (Wilcock 1998). Occupations are defined as all the things people do everyday that are purposeful, meaningful and culturally relevant (Christiansen and Townsend 2004). Through what they do, people develop skills, meet basic needs, satisfy the intrinsic need for mastery and competence, and attain group acceptability (COT 2006). Occupations are important in developing personal and social identity (Yerxa et al 1989). Taylor (2003) suggested that the occupational component of leisure impacts on an individual's concept of self, and that group membership confers both a social and a self identity.

\section{Meaning}

It is the human relationship with occupation for health that forms the basis for occupational science (Wilcock 1998). The categorisation of occupation must include the concept of meaning to be congruent with this innovative paradigm (Persson et al 2001). Participation in meaningful occupations can further give individuals a sense of purpose in their lives (Christiansen and Townsend 2004).

Wilcock (1998) explicated the need for occupation to be purposeful and balanced, not only in self-care, productivity and leisure, but also in people's unique capabilities and interests, as well as in their physical, social and mental needs.

A more explicit focus on meaning and value dimensions in different occupations (Persson et al 2001) will ensure that the relevance of meaningful outcomes are not lost in occupational therapy practice. Furthermore, understanding meaning allows occupational therapists to analyse which occupations to choose for specific therapeutic purposes (Hvalsøe and Josephsson 2003).

\section{Walking}

Walking is one of the easiest, safest and most inexpensive forms of exercise (Richardson et al 2005). It can be done almost anywhere and almost anyone can do it, so it can be readily incorporated into daily routine (Richardson et al 2005, Department of Health [DH] 2011). There is growing evidence that walking improves health and psychological wellbeing (McDevitt et al 2005, Richardson et al 2005, Dawson et al 2006, Mind 2007, Roe and Aspinall 2011). The Walking the way to Health Initiative (WHI) and Walk4Life campaigns (Wilde et al 2001, DH 2011) aimed to improve the health and wellbeing of the general public through walking.

The benefits of physical activity depend on the individual, the activity, and the environmental and social context in which it takes place (Wilde et al 2001). An evaluation of the WHI scheme found that walking made people "feel healthier, more "alive" and increasingly socially connected' (Dawson et al 2006, pp3-4). Such communitybased activities enhance social networks and social support (Reger-Nash et al 2006). Yet health promotion literature recommends greater focus on walking as a pleasurable leisure activity to increase participation (Bird 2005).

Physical activity improves fitness and psychological wellbeing (Clingerman 2003). Walking decreases anxiety and depression (Wilbur et al 2009), reduces blood pressure, cuts the risk of stroke and increases functional capacity, protecting against cardiovascular disease (Tully et al 2005). This protective effect has greater significance in older adults with diabetes (Smith et al 2006).

Walking improves the quality of life of people with serious mental illness by alleviating psychiatric disability, improving social skills and assisting integration into the community (Richardson et al 2005). Consequently, it has a key role as a preventative and therapeutic intervention in tackling mental distress (Mind 2007) and promoting physical health benefits.

This study, therefore, aimed to identify the occupational benefits of walking, to evidence using walking in therapeutic practice, and to gain a greater understanding of individual meanings and experiences of walking as a leisure occupation.

\section{Method}

A qualitative research design was adopted using semistructured interviews, with questions developed with reference to the Model of Human Occupation (Kielhofner 2008). Analysis was guided by the interpretative phenomenological approach (Smith and Osborn 2003). Qualitative methodology is concerned with elucidating the experiences and meaning 'that people give to dimensions of their lives and social worlds' (Hewitt 2007, p1149), and attempting to explain those experiences. Interpretative phenomenological analysis (IPA) is used to elicit the meaning structure of a phenomenon (Smith and Osborn 2003).

\section{Participants}

Ethical approval was obtained through the authors' host institution's research ethics process. Participants gave informed written consent. Confidentiality was assured and pseudonyms were used to ensure anonymity. Participants were made aware that they could withdraw at any time, ask for their data to be destroyed without any consequences at a later date, and that selected quotes would be used in research dissemination.

The sample consisted of six healthy volunteers selected by convenience sampling. All were members of the university's walking club and were students of Caucasian descent. Two were male and four female, with mean ages ranging from 21.0 to 34.5 years. Two of the females were Dutch and the rest were British. Based on Smith's and Osborn's (2003) advice that small sample sizes provide adequate data in qualitative studies, six participants was deemed a proportional representation for this study.

Participants were purposively selected as individuals who, at the time of data collection or in the past several years, engaged in walking as a leisure occupation. 


\section{Procedure}

In-depth semi-structured interviews were used to capture the rich data needed to analyse the meaning of walking (Pope and Mays 2000). Each participant was involved in a 30-60 minute interview at a mutually convenient location. All interviews were digitally recorded and transcribed verbatim. The questions related to participants' experiences of walking: how long they had walked and how often; what interested them in walking and why it was important; and their walking preferences and the images that walking provoked.

\section{Data analysis}

Interviews were transcribed fully, and read and re-read to sensitise the authors to major themes. Each transcript was analysed in detail before examining the others. Initially analytical comments were noted in the left-hand column and emerging themes in the right, to understand content and complexity rather than frequency (Smith and Osborn 2003). Phenomenological themes were listed in chronological order to identify connections between them and any similarities between participants' views or experiences. Theoretical ordering allowed these to be clustered into broader interpretative themes. The transcripts were checked to ensure that clustered themes complemented participants' actual words. All transcripts were analysed and a final table of themes was produced and ordered, with quotes that captured most strongly the respondents' concerns, together with key words and page and line number (Smith and Osborn 2003).

\section{Trustworthiness}

Credibility of the data was addressed by sending a summary of the themes to participants. This ensured that the data analysis was congruent with the participants' experiences, thereby reducing researcher bias and showing an authentic representation of their occupational experiences (Hewitt 2007).

A reflective journal was used to capture any learning and changes of thinking that might have taken place.

\section{Findings}

Walking held a number of different meanings for participants; however, there were similarities as well as unique accounts (see Table 1).

Participants provided numerous examples of using walking to seek out, establish and maintain contact with other people, to increase their physical fitness, and to relax, escape and problem solve. Some participants revealed the sense of mastery and feelings of achievement from climbing up a steep mountain, and others expressed the impact of positive feelings from engaging with the natural environment. Some participants also provided negative accounts of walking in a group.

Physical occupations clearly hold many therapeutic benefits through addressing the emotional and social, as well as physical, elements of health and wellbeing.
The themes are illustrated in tables, using pseudonyms and quotes indicating the page and line number of the interview transcripts.

\section{Social \\ connectedness}

\section{Building new social relationships and a medium for social interaction}

One of the main motivations for participants to engage in walking was to meet people and to make new friends. Often these new relationships were maintained outside the immediate walking group (Joe 1.15). Participants provided examples of using walking to seek out, establish and maintain contact with other people. These social relationships were sought after and established due to mutual interests. Walking was also a source of motivation. The motivation provided by a fellow walker enabled Joe to achieve his goal of reaching the top of the hill (Joe 12.25). Being part of a walking group provided opportunities to improve social interaction skills (Sophie 6.6). In between were nested occupations where interactions were built on specific situations, such as having a meal together, going ice skating or bowling, or going to the pub (Sophie 14.39).

\section{Table 2. Social connectedness}

Joe 1.15 'I've enjoyed it because I've made quite a lot of friends just
that I see outside of the environment.'

Joe 12.25

'... really steep incline, rock climbing and I found that really difficult but I was doing it with another guy and we were both kind of like spurring each other on and so I found that really, really, helpful, I mean if I'd been doing that on my own I might not have be able to get up there I think.'

Sophie 6.6 ' '... due to the walking club, really I think learned things, how to behave socially, but that's more within the club itself so it's not really to do with the walking itself.'

Sophie 14.39 '... but it's like also ... social things, going ice skating, going erm, going bowling or erm or just going to a pub ... sometimes it doesn't have anything to do with walking it's just a group of friends that you made.'

The idea that a group has a particular 'identity' mirrors Taylor's (2003) research, which recognised that leisure has personal and social meanings. Groups are placed into social categories and assigned certain assumed attributes, which may also be called social stereotypes (Taylor 2003). Walking was sought out specifically by Joe because he had stereotyped walkers as being 'outdoorsy'. Through walking, therefore, Joe was able to express who he was, indicating that social relationships are perhaps established and maintained through a shared occupational interest. 


\section{Group membership}

The role of the group appeared to be significant in the development of the meaning of walking. Group membership conferred a social identity and a sense of belonging. Being part of a group gave participants a purpose to walking and embodied feelings of support and motivation (Emma 9.9). As a result of joining the group, members participated in activities they would not ordinarily have done (Jodie 8.33).

Despite this, there were negative aspects to walking in a group (Emma 8.30). Although some participants relished the support and encouragement group membership brought, others felt a reduced sense of pleasure because of the physically demanding nature of walking. Emma would stop walking in the group if she felt that she could not keep up with the others, because it would diminish her sense of enjoyment (8.30).

Table 3. Group membership

\begin{tabular}{c}
\hline Emma $9.9 \quad$ '... if I had not found the walking club then you know \\
maybe I could have walked a lot less.'
\end{tabular}

Jodie 8.33 'If I was in a group of people I would be less likely to make a big deal out of it, and more likely to have a go.'

Emma 8.30 'I might not even do it, because I wouldn't enjoy it as much if I knew everyone was waiting for me.'

Grace 14.18 'I know it feels really bad to fall behind and that's what also keeps on motivating me to go as fast as I can.'

John 13.17 'It is a little annoying when people come on walks they really shouldn't because they don't have the ability or physical fitness because it does slow down the whole group.'

Members of a group influenced the self-confidence of an individual. If performance is valued by the group, individuals feel worthy (Christiansen and Townsend 2004). The experiences shared by those who fell behind indicated feelings of inadequacy and guilt for holding the group back. Others felt frustrated, if only implicitly, towards these 'slower' members. This gave rise to feelings of disappointment, which had a negative psychological impact (Emma 8.30). This was evident when Grace chose not to walk the following day, but, for Grace, the knowledge of what it felt like to fall behind was also a source of motivation (14.18).

It seems that the group aspect of walking played an important role in developing these participants' self-confidence, which resonates with Christiansen's and Townsend's (2004) view that groups can increase individual self-confidence and self-efficacy. However, engaging in an activity beyond an individual's capability can be detrimental to feelings of self-worth and self-confidence.

These participants' encounters suggest that people may stop participating if the occupation becomes too demanding. Furthermore, if the group's level of performance varies too widely, this may unintentionally reinforce negative feelings of failure.

\section{Walking and talking}

Communication while walking was important to share experiences, although the need for social communication was expressed by some more than others. Some aspects of walking were too personal to share verbally. The social aspect of walking gave participants a different platform on which to communicate. People were more able to discuss different or difficult topics while walking as opposed to another social setting.

Occupational therapists assert a unique focus on occupation, which allows, as these findings suggest, a different, perhaps more natural, way in which people can discuss and share their problems. This shows not only how important occupation is as a communication tool but that it can facilitate an understanding of people's experiences in context.

\section{Wellbeing}

The second main theme was wellbeing. The meanings attributed to positive wellbeing were related to experiences of solitude, social connections, nature, mastery and a challenge. All of these were elements included in other themes.

\section{Emotional wellbeing}

Walking was seen as enjoyable and was a source of these positive feelings (Table 4). Participants discussed how walking made them feel more positive and happier (Joe 5.34, Jodie 5.9). Walking was a way to work through problems, a means of relaxation and a distraction to other things that might be going on in their life (Grace 8.11, Emma 7.1). Emma described the 'transformative' feeling when she saw beautiful scenery to depict the positive impact walking had on her emotionally.

\section{Table 4. Emotional wellbeing}

\section{Joe $5.34 \quad$ ' ... it kind of helps your mind a bit I always felt that} after kind of a weekend walk or a day walk I'd feel a lot happier, just be bouncing about the house.'

Jodie 5.9 'I just think you feel like a million dollars when you've been for a walk.'

Grace 8.11 ' '... it just completely takes your mind off everything that's going on.'

Emma 7.1 'I might choose to walk on my own if that's the case, perhaps if I've got something to think through, or if I feel a strong sense of emotion and I need to try and work through that emotion.'

\section{Physical wellbeing}

All participants experienced walking as time well spent, and stressed its importance as a focus on physical performance (Table 5, Jodie 1.8). Despite positive feelings and a sense of wellbeing promoted by physical exertion, several participants had an ambiguous relationship with walking because of its physical nature. For example, Sophie stressed that she did not like the physical aspect of walking (Sophie 2.11). However, others specifically chose walking for this purpose. A key aspect of enjoyment for some participants came from the sense of achievement of physically working their body (Emma 5.9). However, some participants also remarked on the 'unconscious' nature of the physical benefits (Joe 1.19). 
Table 5. Physical wellbeing

\begin{tabular}{ll}
\hline Jodie 1.8 & $\begin{array}{l}\text { 'Obviously, it helps to keep you fit so erm it's a form of } \\
\text { exercise that is quite good for you.' }\end{array}$ \\
John 2.32 & 'I do enjoy the kind of like sweating up a hill.' \\
Sophie 2.11 & 'I don't like the ... physical sort of walking ... you get \\
sweaty and you're tired and your muscles hurt.' & 'It's a pain of achievement.' \\
Emma 5.9 1.19 & $\begin{array}{l}\text { 'I suppose it does keep you fit, but it's not something } \\
\text { Jou tend to realise you are doing exercise.' }\end{array}$ \\
\hline
\end{tabular}

Although for some walking was a way to use their bodies productively, the physical aspect of walking was an added extra, demonstrating how individuals perceive and interpret their occupations in different ways. This supports the multidimensional nature of occupation (Wilcock 1998, Molineux 2004) by indicating that leisure is more than just nourishment for the physical body; as Mosey (1996) pointed out, individuals pursue and endeavour to attain something more.

\section{Escape}

Participants perceived walking as a means to escape from the city and everyday problems and to promote wellbeing:

It's a nice way of getting away from everything switching off and relaxing (Jodie 1.19).

The participants' accounts of escape were substantiated through phrases such as 'feel free', giving weight to the theory that walking improves people's psychological wellbeing, as suggested by Dawson et al (2006).

\section{De-stressing}

Besides physically getting away, walking itself and the environment brought intrinsic satisfaction. It enabled participants to escape physically the problematic aspects of their everyday life and to separate mentally the stressful part of the day from the more pleasurable part:

It is quite important, it's how I can switch off and relax I think that I can feel myself de-stressing when I get out into the countryside and walking (Jodie 2.13).

The potential role of meaningful occupations in mediating stress has received little attention in the literature. Physical activity in a natural environment is an effective way to relieve stress (Roe and Aspinall 2011). However, these participants indicate that the stress-relieving benefits of walking are multifaceted. The effect of de-stressing appears to relate to individualised meaning of the occupation and environment.

\section{Achievement from a challenge}

Participants demonstrated feelings of achievement gained through challenging themselves, giving a sense of purpose, satisfaction and pride in reaching an end goal, such as the top of a mountain (Table 6, Grace 2.25). For some, this pleasure was associated with a sense of self-actualisation, by proving that they could achieve their goal and, in turn, promote feelings of self-worth and self-esteem (Grace 2.34).
Table 6. Achievement from a challenge

Grace 2.25 'I can't go any longer and then I still continue and then
I'll be on the top and I'm like yes I made it, and you see
the view and it's beautiful.'

Grace 2.34 '... proving yourself to yourself or achieving something that is just so great and it feels really good to do that.'

\section{Connection to nature}

All participants considered aspects of nature or the environment when disclosing their pleasure in walking (Table 7). Seeing a beautiful landscape was something to strive for and added to their sense of achievement. Participants reflected on how this connection to nature made them feel. Such experiences were always positive and added an element of either excitement (John 3.11) or peacefulness and tranquillity (Joe 3.9). Walking gave the opportunity to explore and master their environment, and was a way to try new things, discover new places and learn about new cultures. Often the newness of a walking environment added to the challenge (Emma 6.7).

This connection to the natural environment characterised the meaning of walking throughout each theme, by reinforcing people's sense of satisfaction, mastery and wellbeing. Consequently, these findings signify the importance of outdoor and countryside walking for positive mental wellbeing, which substantiates research by Roe and Aspinall (2011) whose innovative research demonstrated the restorative effect of nature and rural walking.

\section{Table 7. Connection to nature}

\begin{tabular}{ll}
\hline John 3.11 & '... if it's, you know, particularly beautiful landscape or \\
Joe 3.9 & ' $\ldots$ it it wastical I think that it gives you a kind of bit of a buzz.' \\
& silence and there was not one sound at all, it was \\
& absolutely amazing.' \\
Emma 6.7 & '... there's a whole other kind of walk, that's also \\
& important to me, but which is nowhere as regular, \\
& which is a kind of challenging walk in scenery that \\
I have never seen before.'
\end{tabular}

\section{Discussion}

This study illustrates a number of positive benefits of walking, and supports it as an intervention in occupational therapy. It illuminates a wide range of further meanings within the walking experience as a leisure pursuit, rather than solely for exercise. Walking provided a means of improving quality of life and wellbeing through enhancing social networks and alleviating daily stressors. Similar to Ball et al (2007), the benefits depended on the individualised meanings of walking, the environment, and the social context in which walking for leisure took place.

Four main themes and nine subthemes emerged from the data, supporting the belief that meaningful occupation 
is complex and multifaceted (Persson et al 2001), and that occupation should be balanced in terms of people's unique capabilities and interests, as well as their physical, cognitive, affective and social needs (Wilcock 1998) for positive health benefits to be seen.

The elements of interaction with the social environment are ever present in the findings, be it making new social connections or maintaining old ones, or through belonging to a group. The social elements of walking are significant to the participants' experiences of meaningfulness. Some benefits may be particular to walking, as Wilde et al (2001) also found that walking increased social networks. However, many similar social experiences may be gained from belonging to a group who share similar personally valued occupations. Previous studies have found that community-based activities in general increase social networks (Reger-Nash et al 2006). Despite this, the social environment further enabled participants to improve social interaction skills and served to confirm personal identity (Taylor 2003).

Walking in a group appeared to be a positive source of social support and a potential motivator to initial engagement and achievement of personal goals. Roe and Aspinall (2011) also found that walking may impact on personal development by implementing and managing personal goals. This emphasises the importance of the social environment in the promotion of physical activity and supports other research that found social support to be motivating in starting and committing to walking (Perry et al 2008).

Although social interaction may be synonymous with positive benefits (Taylor 2003, Ball et al 2007), this research found that aiming beyond the participant's physical capabilities had a negative impact on his or her self-esteem and confidence. If the physical demands are more than the capabilities of the person, the occupation may be stopped. This is corroborated by Hvalsøe and Josephsson (2003), where people with long-term mental illness excluded occupations when the demands were too high. Roe and Aspinall (2011) found that being challenged was a positive experience for some but not for others, speculating that if a challenge is too demanding this may lower self-esteem.

If walking groups are to be used therapeutically, care should be taken to ensure that the essence of the meaning for the individual is maintained and the client's physical capabilities are considered.

Wellbeing is identified as a major theme in this study. Although it is generally agreed that walking has a physical benefit (Clingerman 2003, Tully et al 2005), it appeared to benefit participants' emotional and psychological wellbeing as well. The physical aspect of walking was a bonus, and was often taken for granted. According to Mosey (1996), although physical occupation is necessary for survival, humans also seek emotional health, freedom, self-knowledge and a sense of belonging. Given that, this study's findings support this ideal, as participants talked in depth about walking as an escape and a distraction, a place of solitude and contemplation, allowing participants to relax and de-stress.
The theme of connection to nature substantiates some of the existing theories that outdoor physical activity benefits health. The intrinsic satisfaction from walking in the country gave participants a sense of fulfilment and positive wellbeing, consistent with other studies (Mind 2007).

Walking met other needs, such as mastery and competence, defined by Wilcock (1998) as a central tenet of occupation. Walking provided sufficient challenges, which allowed participants to engage fully with their occupation and, hence, brought about a sense of achievement and feelings of self-actualisation.

This study demonstrates the complexity of occupation and builds on existing understandings that occupation is individually defined, valued and given meaning (Turner 2007), further illustrating the benefits to health and wellbeing through engaging in satisfactory and meaningful occupations.

\section{Strengths and limitations}

This study used semi-structured interviews and IPA to gather and analyse data, which suited the nature of the topic. As Wilcock (1998) explained, human occupation is too complex and too varied to be explored with simple reductionist techniques.

The study's credibility was enhanced through reflexivity. The reasonable level of consistency in themes and the congruency with previous findings give confidence in certain shared experiences.

There is the possibility of bias given the researcher's background in occupational therapy. Thus emergent themes may have an unintentional occupational focus.

The method of sampling was not totally unsatisfactory. Relying on students and a university walking club was suitable to obtain easily participants who walked for leisure. However, although every effort was made to find a wide range of participants, the sample could not be said to be a true representation of the general population.

Several recommendations for further research have arisen from this study. Further enquiry is recommended into whether individuals with mental health or severe physical impairments would gain similar positive health outcomes from outdoor activity. It may also be of interest to explore further the stress-relieving benefits of walking in a healthy population. As this study focused on the members of a walking group, it may be interesting to look at the health impact of walking alone. Finally, it is recommended that future research look at barriers and motivators to walking, to inform practitioners and public health bodies on how to encourage and sustain walking.

\section{Policy implications}

The occupational benefits of walking may help to focus and develop health promotion policy in encouraging walking as a pleasurable leisure activity, which Bird (2005) suggested is key to increased participation.

Occupational therapists should seize the opportunity and be among those leading the development of prevention and 
wellness programmes (Wilcock 1998). The outdoors played an important role in wellbeing, and it is imperative that policy focuses on facilitating access to rural walking. Occupational therapists could contribute by making recommendations to local councils on disabled-friendly routes, the appropriate level of challenge for different populations, access to physical leisure occupations and inclusive environmental design.

Occupational therapists would be well placed in general practice to assist in prescribing the right type of physical activity. They could evaluate both the leisure/physical activity and its requirements for the individual's needs and wants, in order to adapt it appropriately to his or her abilities (Fenech 2008). The expertise that occupational therapists possess could also be used in developing age-appropriate physical activities, for example, community-based walking groups. Furthermore, occupational therapists could take a consultancy role in educating public health bodies on the health-promoting benefits of engaging in purposeful and meaningful occupations. However, all this can only be achieved through building a sound evidence base for the impact that productive leisure occupations have on health and wellbeing (COT 2008).

Finally, the promotion of physical activity in clinical settings is rarely allocated to the role of occupational therapists. However, occupational therapists could play a key role in planning, promoting and facilitating engagement in physical activity in clinical settings. In community and rehabilitation settings, occupational therapists could assist clients to develop the skills required for their chosen physical activity, such as social interaction skills, or establish a resource pack to signpost clients to suitable physical activities.

\section{Conclusion}

This study aids the understanding of the meaning and potential role of walking and active leisure occupations in occupational therapy. It can inform occupational therapists of the value of walking, indicating the physical benefits and promoting psychological and social wellbeing through walking with a group in a rural setting. These results also highlight the possible negative consequences of being part of a walking group. It is important for occupational therapists, therefore, to promote active leisure occupations while being mindful of the need to be client centred and to focus on individualised meaning. Finally, it acts as a reminder of the health benefits of engaging in meaningful occupation, which could be a prerequisite to preventive health promotion.

\section{Acknowledgements}

Thanks are extended to the student participants. This paper is based on work submitted for a MSc in Occupational Therapy at Leeds Metropolitan University. Conflict of interest: None declared.

\section{References}

Ball M, Corr S, Knight J, Lowis MJ (2007) An investigation into the leisure occupations of older adults. British Journal of Occupational Therapy, 70(9), 393-400.

\section{Key findings}

- Walking has physical and psychological benefits.

- Occupational therapists should consider walking as a valuable intervention.

- Occupational therapists could have a consultancy/educative role in promoting and facilitating active leisure occupations in clinical settings.

\section{What the study has added}

The study illustrates the positive benefits of walking for leisure and highlights the need to remain occupationally focused. It further suggests that occupational therapists have a role to play in health promotion.

Bird W (2005) Walking the way to health. Evidence-Based Healthcare and Public Health, 9(2), 171-72.

Christiansen CH, Townsend EA (2004) Introduction to occupation: the art and science of living. Upper Saddle River, NJ: Prentice Hall.

Clingerman EM (2003) Participation in physical activity by persons living with HIV disease. Journal of the Association of Nurses in AIDS Care, 14(5), 59-70.

College of Occupational Therapists (2006) Recovering ordinary lives: the strategy for occupational therapy in mental health services 2007-2017, a vision for the next ten years. London: COT.

College of Occupational Therapists (2008) Health promotion in occupational therapy. London: COT.

Dawson J, Boller I, Foster C, Hillsdon M (2006) Evaluation of changes to physical activity amongst people who attend the Walking the way to Health Initiative (WHI) - prospective survey. Oxford: Oxford Brookes University School of Health and Social Care/The Countryside Agency.

Department of Health (2011) Walk4Life. Available at: $h$ ttp://uww.walk4life.info/ Accessed 31.07.11.

Di Bona L (2000) What are the benefits of leisure? An exploration using the Leisure Satisfaction Scale. British Journal of Occupational Therapy, 63(2), 50-58.

Fenech A (2008) The benefits and barriers to leisure occupations. NeuroRehabilitation, 23(4), 295-97.

Hewitt J (2007) Ethical components of researcher-researched relationships in qualitative interviewing. Qualitative Health Research, 17(8), 1149-59.

Hvalsøe B, Josephsson S (2003) Characteristics of meaningful occupations from the perspective of mentally ill people. Scandinavian Journal of Occupational Therapy, 10(2), 61-71.

Johnson JA (1996) Occupational science and occupational therapy: an emphasis on meaning. In: R Zemke, F Clark, eds. Occupational science: the evolving discipline. Philadelphia: FA Davis.

Kielhofner G (2008) Model of Human Occupation: theory and application. 4th ed. Philadelphia: Lippincott Williams and Wilkins.

McDevitt J, Wilbur JE, Kogan J, Briller J (2005) A walking program for outpatients in psychiatric rehabilitation: pilot study. Biological Research for Nursing, 7(2), 87-97.

Mind (2007) Ecotherapy: the green agenda for mental health. Available at: www.mind.org.uk/mindweek Accessed 17.02.10.

Molineux M (2000) Occupation for occupational therapists. Oxford: Blackwell Publishing.

Mosey AC (1996) Psychosocial components of occupational therapy. New York: Lippincott Williams and Wilkins.

Perry CK, Rosenfeld AG, Kendall J (2008) Rural women walking for health. Western Journal of Nursing Research, 30(3), 295-316. 
Persson D, Erlandsson LK, Eklund M, Iwarsson S (2001) Value dimensions, meaning and complexity in human occupation - a tentative structure for analysis. Scandinavian Journal of Occupational Therapy, 8(1), 7-18.

Pope C, Mays N (2000) Qualitative research in health care. 2nd ed. London: BMJ Books.

Reger-Nash B, Bauman A, Cooper L, Chey T, Simon KJ (2006) Evaluating communitywide walking interventions. Evaluation and Program Planning, 29(3), 251-59.

Richardson CR, Faulkner G, McDevitt J, Skrinar GS, Hutchinson DS, Piette JD (2005) Integrating physical activity into mental health services for persons with serious mental illness. Psychiatric Services, 56(3), 324-31.

Roe J, Aspinall P (2011) The restorative benefits of walking in urban and rural settings in adults with good and poor mental health. Health and Place, 17(1), 103-13.

Smith JA, Osborn M (2003) Interpretative phenomenological analysis. In: JA Smith, ed. Qualitative psychology: a practical guide to research methods. London: Sage, 51-80.

Smith TC, Wingard DL, Smith B, Kritz-Silverstein D, Barrett-Connor E (2006) Walking decreased risk of cardiovascular disease mortality in older adults with diabetes. Journal of Clinical Epidemiology, 60(3), 309-17.
Taylor J (2003) Women's leisure activities, their social stereotypes and some implications for identity. British Journal of Occupational Therapy, 66(4), 151-58.

Tully MA, Cupples ME, Chan WS, McGlade K, Young IS (2005) Brisk walking, fitness, and cardiovascular risk: a randomised controlled trial in primary care. Preventative Medicine, 41(2), 622-28.

Turner A (2007) Making assumptions about meaningful and purposeful occupations. In: A Turner, M Foster, SE Johnson, eds. Occupational therapy and physical dysfunction. Edinburgh: Churchill Livingstone.

Wilbur J, Zenk S, Wang E, Oh A, McDevitt J, Block D, McNeil S, Ju S (2009) Neighbourhood characteristics, adherence to walking, and depressive symptoms in midlife African American women. Journal of Women's Health, 18(8), 1201-10.

Wilcock A (1998) An occupational perspective of health. Thorofare, NJ: Slack. Wilde BE, Sidman CL, Corbin CB (2001) A 10,000-step count as a physical activity target for sedentary women. Research Quarterly for Exercise and Sport, 72(4), 411-14.

Yerxa EJ, Clark F, Frank G, Jackson J, Parham D, Pierce D, Stein C, Zemke R (1989) An introduction to occupational science, a foundation for occupational therapy in the 21st century. Occupational Therapy in Health Care, 6(1), 1-17.

\section{Letters to the editor}

\section{Open access and the future of BJOT}

Madam,

I am grateful to Duncan (2012) for raising concerns about the future format of the British Journal of Occupational Therapy (BJOT). The Editorial Board shares some of his concerns and looks forward to the forthcoming survey for members of the British Association of Occupational Therapists (BAOT) to express their opinions on this topic. Readers who are not members are welcome to contact us with their views.

Duncan (2012) refers to open access to research published in BJOT. Currently, the print version of BJOT is sent to members and around 600 subscribers throughout the world. Free online access to download PDFs of articles published in BJOT is available to members of BAOT as one of their member benefits; to subscribers; to members of other occupational therapy associations through reciprocal arrangements; and to people in certain developing countries though the HINARI programme. Other readers have to pay per downloaded article. Journals published by commercial organisations also charge for access to articles.

Kolehmainen (2011) originally raised the issue of open access and warned that researchers were prevented from submitting their research for publication in BJOT as open access was a condition of many funding councils. A recent report (Department for Business Innovation and Skills 2011) indicates that the government wants to achieve free access to publicly funded research. Mindful of these views, the Editorial Board has sought ways to allow open access to some research articles. Therefore, our forthcoming revised Author's Guide will indicate that where a research grant requires that results are freely disseminated, this can be negotiated on an individual basis. The manuscript will be submitted and peer reviewed in the usual way and negotiations will occur if and when the manuscript is accepted for publication.

\section{Christine Craik,}

Chairman, Editorial Board.

Department for Business Innovation and Skills (2011) Innovation and Research Strategy for Growth. Available at: http://www.bis.gov. uk/assets/biscore/innovation/docs/il111387-innovation-and-research-strategy-forgrowth.pdf Accessed 01.02.12.

Duncan E (2012) Moving BJOT to online only. British Journal of Occupational Therapy, 75(1), 45.

Kolehmainen N (2011) Journal quality metrics. British Journal of Occupational Therapy, 74(5), 258. 